\title{
Socioeconomic inequalities in lung cancer - a time trend analysis with German health insurance data
}

\author{
Fabian Tetzlaff ${ }^{*}$ (D), Jelena Epping ${ }^{2,3}$, Juliane Tetzlaff ${ }^{2}$, Heiko Golpon $^{4}$ and Siegfried Geyer ${ }^{2}$
}

\begin{abstract}
Background: Lung Cancer (LC) is one of the most prevalent cancer diseases. Due to the lack of databases which allow the combination of information on individual socioeconomic status (SES) and cancer incidence, research on social inequalities in LC among the German population is rare. The aim of the study is to analyse time trends in social inequalities in LC in Germany.

Methods: The analyses are based on data of a large statutory health insurance provider. The data contain information on diagnoses, occupation and education (working age), and income (full age range) of the insurance population. Trends were analysed for two subpopulations (retirement age and working age) and stratified by sex. The analyses are based on incidence rates and proportional hazard models spanning the periods 2006-2009, 2010-2013 and 2014-2017.

Results: Incidence rates declined in men but increased in women. For men, inequalities were strongest in terms of income and the decline in incidence was most pronounced in middle- and higher-income men. Among women at retirement age, a reversed income gradient was found which disappeared in the second period. The educational gradient among the working-age population decreased over time due to the trend towards increasing incidence among individuals with higher education. Declining gradients were also found for occupational position.

Conclusion: The findings reveal considerable inequalities in LC and that trends vary with respect to SES, sex and age. Widening income inequalities were found in the retired population, while educational and occupational inequalities tend to narrow among the working-age population.
\end{abstract}

Keywords: Lung cancer, Time trend, Incidence, Socioeconomic inequalities, Germany

\section{Background}

Lung cancer (LC) is one of the most common cancer diseases and ranks among the most frequent causes of death in Germany $[1,2]$. With regard to the development of incidence over time, different trends were observed for men and women. In the last decades, a decreasing number of incident cases was reported for men. In contrast, the yearly incidence in women rose continuously [2-4]. The strong link between socioeconomic status (SES) and

\footnotetext{
* Correspondence: tetzlaff.fabian@mh-hannover.de

${ }^{1}$ Institute for General Practice, Hannover Medical School, Hanover, Germany Full list of author information is available at the end of the article
}

morbidity has been emphasised in many studies (e.g. for Germany $[5,6])$. International studies show that there are also strong inequalities with regard to LC, especially among men [7-16]. So far, however, little is known on how social inequalities in the incidence of LC developed over time. This holds especially true for Germany.

Few international studies investigated trends in social inequalities in LC morbidity and mortality. These studies mostly reported increasing social inequalities for men and women $[11,12,15,16]$. Studies investigating social inequalities in the incidence of LC among the German population are rare. This is due to the fact that the data

C C The Author(s). 2021 Open Access This article is licensed under a Creative Commons Attribution 4.0 International License, which permits use, sharing, adaptation, distribution and reproduction in any medium or format, as long as you give appropriate credit to the original author(s) and the source, provide a link to the Creative Commons licence, and indicate if changes were made. The images or other third party material in this article are included in the article's Creative Commons licence, unless indicated otherwise in a credit line to the material. If material is not included in the article's Creative Commons licence and your intended use is not permitted by statutory regulation or exceeds the permitted use, you will need to obtain permission directly from the copyright holder. To view a copy of this licence, visit http://creativecommons.org/licenses/by/4.0/ The Creative Commons Public Domain Dedication waiver (http://creativecommons.org/publicdomain/zero/1.0/) applies to the data made available in this article, unless otherwise stated in a credit line to the data. 
required for such analyses are scarce as official cancer registries do not include socioeconomic information of the diseased individuals. Current research from Germany based on cross-sectional data investigates whether social deprivation, measured by regional levels of income, education, and labour force participation, is associated with cancer. For these analyses, the macro-level information on regional social deprivation on district level was combined with cancer site-specific incidence rates. For LC, a social gradient was found in men but not in women [9]. However, as this solution is susceptible to ecological fallacies, the use of SES information on individual level should be preferred whenever possible. Furthermore, studies analysing time trends in SES inequalities in LC incidence in the German population are still lacking. Our study aims to step into this gap by using individual data on SES and incidence to examine time trends in inequalities in LC in Germany.

From a life course perspective, the cumulative disadvantaging effects of potentially harmful behaviours determine the outcome of social inequalities in health and mortality in later life [5, 17-19]. This holds especially for the harmful effects of smoking, as the risk of developing smoking-related diseases increases with the duration of smoking. The earlier individuals start smoking the more likely they are to suffer from a smoking-related disease later in life [20, 21]. Until the 1970s, smoking became more and more common but increasingly restrictive tobacco control policies in the 1990s and later had led to declining smoking rates, especially among highly educated individuals $[17,18,21-26]$. This development also had a positive impact on trends in mortality and life expectancy [27]. At the same time, smoking rates among individuals with low SES were quite stable or decreased at a slower pace than the rates among highly educated individuals [21, 26]. Moreover, a convergence of smoking rates between men and women has been observed in many industrialised countries since the 1960s and 1970s $[18,21,25]$. This convergence is rooted in changes in the social position of women and the adoption of risky health-related behaviours [18, 21, 25, 28, 29]. This has led to declining differences in smoking-related morbidity between men and women [13, 18, 21, 25, 28-32]. As a result, the burden of smoking-related diseases can be expected to concentrate in groups with lower SES. However, since the trends in smoking vary between sex and age groups, differing trends in social inequalities in LC incidence between men and women may also be expected [21, 33].

Due to data restrictions, many studies combined different indicators of SES (e.g. income, educational level, and occupation) into a single deprivation index. However, previous research has shown that these indicators measure different aspects of social inequality and should therefore be analysed independently whenever possible [34].

The aim of the study is to investigate time trends in LC incidence in Germany. Special attention will be paid to time trends of social inequalities in incidence and whether these trends differ between men and women, and between younger and older age groups. The analyses are based on claims data of a large German statutory health insurer, which contains large case numbers and different information on SES characteristics of the insured individuals.

The study is guided by the following research questions:

1. Are there socioeconomic inequalities in lung cancer incidence? Do these inequalities exist in men and women, and all age groups equally?

2. Are there different time trends in lung cancer incidence between socioeconomic groups? Are these trends in inequalities similar in men and in women?

\section{Methods \\ Data}

In this study, claims data of a large statutory health insurance provider (AOK Niedersachsen $[\mathrm{AOKN}]$ ) were used, which insures approximately one third of the inhabitants of the federal state Lower Saxony [35]. The data of the years 2005 to 2017 were available for our analyses. As the number of incident cases of LC in the different SES groups was limited, single calendar years were sumarised into three time periods (2006-2009, 2010-2013 and 2014-2017). While it had been shown that the age and sex distribution of the insurance population is comparable to those of the total German population, individuals with low income and lower occupational position are overrepresented [36]. More detailed information on data characteristics can be found in previous studies [37-40]. The analyses were performed for all individuals aged 20 and older.

\section{Definition of lung cancer incidence}

According to a previously published study based on the same data [39], cases of LC were identified based on the occurrence of an in- or outpatient LC ICD-10 diagnosis (C34.0 to C34.9) in the individual insurance history. Incident cases were defined for individuals having a LC diagnosis in the respective time period and who had a LC diagnosis-free period of at least 90 days preceding their initial diagnosis.

\section{Definition of socioeconomic indicators}

Since insurance fees are based on the level of the individual income, the data contain information on the 
annual gross income from salaries and pension payments. Furthermore, information on educational level and occupational position is available for the employed population. Previous research has shown that each SES indicator depicts a different aspect of social inequalities and should thus not be used interchangeably due to their moderate or weak correlation [34, 41]. Therefore, each of these indicators was analysed separately to gain a deeper understanding of the underlying processes in SES inequalities in LC.

\section{Income groups}

The income information contained in the data is based on the individual annual income reported to the insurer by the employer (working population) or by the Federal Pension Fund (retired population) [37-40]. Self-employed persons were also included in the analyses, as their insurance contributions also depend on their gross earnings [37-40]. As in previous studies, we defined income in relation to the German average income of a given year and adjusted it for inflation, which allows direct comparability over time as the purchasing power is kept constant [3740]. Individuals were classified into three income groups according to their relative income level: Individuals with less than $60 \%$ of the German average income were assigned to the low, with 60 to $80 \%$ to the middle, and with more than $80 \%$ to the higher-income group [38]. The case number underlying the analyses of income inequalities in LC are presented in Table 1.

\section{Educational level}

Educational level was defined using the years of schooling, which refer to different levels of school-leaving qualifications: 9 to 11 (low educational level), and 12 to 13 (high educational level) years of schooling. Since information on educational attainment is only available for the working-age population, the analyses of educational inequalities in LC incidence were limited to the age range 20 to 65 (Table 2).

\section{Occupational position}

We defined occupational position according to the occupation classification system proposed by Blossfeld [42] Within this system, individuals of the same occupational group are similar in terms of school-leaving qualification, vocational training, and professional activity. Due to the limited case numbers, we decided to combine the original 12 occupational subgroups into three groups: 1) unskilled, 2) skilled, and 3) specialists and highly qualified individuals. Individuals in the middle group usually have at least vocational training but no management function. In contrast, specialists and highly qualified individuals usually have a higher qualification (special professional training or university degree, e.g. bachelor or master level) and a higher level of decision latitude. The analyses concerning occupational inequalities in LC are also restricted to the working-age population (Table 2).

\section{Statistical analyses}

Social inequalities in incidence risks were estimated using a two-stage approach, which has been well applied in previous studies (e.g. [37, 39, 40]). First, general inequalities in LC incidence risks among men and women were estimated by combining the data of the three periods and fitting parametric exponential proportional hazard regression models with constant baseline hazard over time. All analyses are controlled for the mean age in the period (as second-degree polynomial) and for period. To test the robustness of our models, we ran the same analyses with cox proportional hazard models, which, however, did not affect the results.

To analyse whether inequalities in LC incidence are age-patterned, we calculated the observed age-specific incidence rates and plotted them against the smoothed predicted incidence rates in a second step. The predicted rates were estimated from parametric proportional hazard models with an exponential distribution using the STATA command "predict" [43]. To examine whether inequalities increased or decreased over time we estimated interaction models (period*SES indicator).

All analyses were performed separately for the population at working age (20-65 years) and for the population at retirement age (66+ years) and for sex using Stata 14 [43]. All confidence intervals were estimated by drawing 1000 bootstrap samples.

\section{Results}

\section{Social inequalities in lung cancer incidence}

With respect to income inequalities, a clear gradient in LC incidence emerged in men at working and retirement age (Fig. 1). Among women, the picture is less clear and the inequality patterns differ considerably between agegroups. While a tendency towards the typical income gradient can also be found among women of working age, the gradient turns at higher ages. Hence, the highest risks of LC incidence among women at retirement age were found for the higher-income group $(\mathrm{HR}=1.2)$ (Fig. 1). With regard to educational inequalities, the analyses reveal that there are clear gradients in both sexes. Men and women with a high educational level have a 26 and 33\% lower incidence risk than individuals with low educational level, respectively (Fig. 1). In men, the risk of developing LC decreases with the level of occupational qualification with the lowest risks among specialists and highly qualified men $(H R=0.7)$. Similar to men, the highest incidence risks were also found among women with the lowest level of occupational qualification (Fig. 1). 
Table 1 Characteristics of the study population aged 20 and older: number of insured individuals, exposures in person-years, number of incident cases, and incidence per 100,000 by income group, time period, and gender

\begin{tabular}{|c|c|c|c|c|c|c|c|c|}
\hline & & & $2006-200$ & & 2010-201 & & 2014-201 & \\
\hline & Income & & Men & Women & Men & Women & Men & Women \\
\hline working age (20-65) & low & no. of individuals & 232,254 & 290,532 & 251,755 & 341,196 & 271,634 & 375,622 \\
\hline & & person-years & 760,708 & $1,001,294$ & 768,372 & $1,104,466$ & 863,493 & $1,285,994$ \\
\hline & & no. of incident cases & 1277 & 611 & 1197 & 781 & 1245 & 850 \\
\hline & & incidence per 100,000 & 168 & 61 & 156 & 71 & 144 & 66 \\
\hline & middle & no. of individuals & 72,486 & 58,126 & 97,185 & 70,631 & 113,485 & 89,995 \\
\hline & & person-years & 250,072 & 208,108 & 313,313 & 240,014 & 392,402 & 323,015 \\
\hline & & no. of incident cases & 192 & 94 & 242 & 105 & 252 & 135 \\
\hline & & incidence per 100,000 & 77 & 45 & 77 & 43 & 64 & 42 \\
\hline & higher & no. of individuals & 235,350 & 63,064 & 294,146 & 83,275 & 346,191 & 116,415 \\
\hline & & person-years & 848,419 & 228,704 & $1,015,157$ & 288,553 & $1,252,295$ & 414,364 \\
\hline & & no. of incident cases & 573 & 103 & 660 & 141 & 721 & 148 \\
\hline & & incidence per 100,000 & 68 & 45 & 65 & 49 & 58 & 36 \\
\hline retirement age $(66+)$ & low & no. of individuals & 131,946 & 309,848 & 147,313 & 301,180 & 142,666 & 283,057 \\
\hline & & person-years & 465,746 & $1,114,705$ & 506,319 & $1,062,912$ & 497,975 & $1,011,342$ \\
\hline & & no. of incident cases & 2957 & 1716 & 3183 & 1847 & 3189 & 2067 \\
\hline & & incidence per 100,000 & 635 & 154 & 628 & 174 & 640 & 204 \\
\hline & middle & no. of individuals & 66,519 & 39,639 & 63,839 & 40,211 & 65,993 & 46,095 \\
\hline & & person-years & 238,302 & 141,400 & 223,701 & 141,509 & 233,868 & 162,445 \\
\hline & & no. of incident cases & 1330 & 267 & 1166 & 282 & 1135 & 288 \\
\hline & & incidence per 100,000 & 558 & 189 & 521 & 199 & 485 & 177 \\
\hline & higher & no. of individuals & 18,310 & 12,635 & 17,545 & 13,268 & 23,468 & 17,277 \\
\hline & & person-years & 65,356 & 45,036 & 61,133 & 46,776 & 84,567 & 61,227 \\
\hline & & no. of incident cases & 347 & 101 & 266 & 101 & 306 & 125 \\
\hline & & incidence per 100,000 & 531 & 224 & 435 & 216 & 362 & 204 \\
\hline full age range $(20+)$ & low & no. of individuals & 364,200 & 600,380 & 399,068 & 642,376 & 414,300 & 658,679 \\
\hline & & person-years & $1,226,453$ & $2,115,999$ & $1,274,691$ & $2,167,378$ & $1,361,468$ & $2,297,336$ \\
\hline & & no. of incident cases & 4234 & 2327 & 4380 & 2628 & 4434 & 2917 \\
\hline & & incidence per 100,000 & 345 & 110 & 344 & 121 & 326 & 127 \\
\hline & middle & no. of individuals & 139,005 & 97,765 & 161,024 & 110,842 & 179,478 & 136,090 \\
\hline & & person-years & 488,375 & 349,508 & 537,014 & 381,523 & 626,270 & 485,460 \\
\hline & & no. of incident cases & 1522 & 361 & 1408 & 387 & 1387 & 423 \\
\hline & & incidence per 100,000 & 311 & 103 & 262 & 101 & 221 & 87 \\
\hline & higher & no. of individuals & 253,660 & 75,699 & 311,691 & 96,543 & 369,659 & 133,692 \\
\hline & & person-years & 913,775 & 273,739 & $1,076,289$ & 335,329 & $1,336,861$ & 475,591 \\
\hline & & no. of incident cases & 920 & 204 & 926 & 242 & 1027 & 273 \\
\hline & & incidence per 100,000 & 101 & 74 & 86 & 72 & 77 & 57 \\
\hline
\end{tabular}

\section{Time trends in social inequalities in age-specific lung cancer incidence rates}

To analyse whether inequalities in LC incidence are agepatterned, age-specific incidence rates were analysed. Between the periods, decreasing age-specific incidence rates in LC were found among men, while the rates increased among women (Fig. 1). Furthermore, incidence rates among men shifted to higher ages which led to an increase in the age of incidence (Fig. 2). 
Table 2 Characteristics of the study population aged 20-65: number of insured individuals, exposures in person-years, number of incident cases, and incidence per 100,000 by educational level, occupational group, time period, and gender

\begin{tabular}{|c|c|c|c|c|c|c|c|c|}
\hline & & & $2006-200$ & & 2010-201 & & 2014-201 & \\
\hline & & & Men & Women & Men & Women & Men & Women \\
\hline Educational & low & no. of individuals & 410,758 & 304,628 & 486,722 & 351,816 & 509,839 & 375,616 \\
\hline & & person-years & $1,330,153$ & $1,014,507$ & $1,509,178$ & $1,117,602$ & $1,751,062$ & $1,291,625$ \\
\hline & & no. of incident cases & 845 & 335 & 1115 & 524 & 1357 & 665 \\
\hline & & incidence per 100,000 & 64 & 33 & 74 & 47 & 78 & 51 \\
\hline & high & no. of individuals & 55,354 & 61,794 & 77,235 & 86,732 & 95,232 & 110,026 \\
\hline & & person-years & 174,158 & 200,030 & 227,245 & 261,709 & 303,379 & 355,062 \\
\hline & & no. of incident cases & 24 & 12 & 53 & 30 & 95 & 59 \\
\hline & & incidence per 100,000 & 14 & 6 & 23 & 11 & 31 & 17 \\
\hline Occupational & unskilled & no. of individuals & 214,665 & 141,850 & 199,094 & 144,150 & 171,384 & 138,432 \\
\hline & & person-years & 665,237 & 454,168 & 565,614 & 436,411 & 489,151 & 439,820 \\
\hline & & no. of incident cases & 571 & 237 & 506 & 282 & 330 & 302 \\
\hline & & incidence per 100,000 & 86 & 52 & 89 & 65 & 67 & 69 \\
\hline & skilled & no. of individuals & 167,548 & 64,081 & 267,444 & 101,476 & 350,375 & 149,766 \\
\hline & & person-years & 558,088 & 212,315 & 848,694 & 319,632 & $1,158,700$ & 492,718 \\
\hline & & no. of incident cases & 260 & 44 & 494 & 100 & 769 & 175 \\
\hline & & incidence per 100,000 & 47 & 21 & 58 & 31 & 66 & 36 \\
\hline & specialist \& & no. of individuals & 59,285 & 108,140 & 92,970 & 147,217 & 122,805 & 187,899 \\
\hline & & person-years & 188,233 & 355,075 & 290,067 & 469,682 & 396,893 & 613,502 \\
\hline & & no. of incident cases & 66 & 98 & 136 & 163 & 148 & 199 \\
\hline & & incidence per 100,000 & 35 & 28 & 47 & 35 & 37 & 32 \\
\hline
\end{tabular}

With respect to changes in income inequalities between the two periods, decreasing incidence rates in the middle- and higher-income groups among men were observed while the rates remained quite stable among men with low incomes (Figs. 1 and 3). A different trend was found in women. In the first period, differences in incidence rates between income groups were small for women at working-age. At older age, a reversed gradient emerged with the highest incidence rates among elderly women having higher incomes. Over time, the gradient turned. In the third period the highest incidence rates were found for women with low incomes at working age (Fig. 3). Accordingly, decreasing incidence risks in women with higher incomes and by decreasing incidence risks in women with low incomes were found (Fig. 1).

Among individuals at working age, a slight increase in incidence rates among highly educated men led to decreasing differences between the educational groups over time. Similar trends were also observed among women (Figs. 1 and 4). With respect to occupational position, decreasing rates in men without vocational training (Fig. 1) led to a convergence between the different occupational groups (Fig. 5). In women, occupational inequalities are less pronounced than in men and tend to decrease over time as rates decreased slightly among women without vocational training (Fig. 5).

\section{Trends of social gradients in predicted lung cancer incidence rates}

To identify whether inequalities narrowed or widened over time and which SES group accounted for these changes, we predicted LC incidence rates for different SES groups in the three time periods 2006-2009, 20102013, and 2014-2017 from interaction models (period*SES indicator). While income inequalities remained largely stable among men at working age, the gradient widened considerably among men at retirement age. This widening is mainly driven by the decline in rates in the middle and even more clearly in the higher-income group (Fig. 6). The reversed gradient observed in women at retirement age in the first period disappeared in the third period. Among women aged 20 to 65, the typical gradient emerged in the third period, indicating widening inequalities over time. In both subgroups, these developments are driven by the strong increase in incidence rates among women with low incomes and 


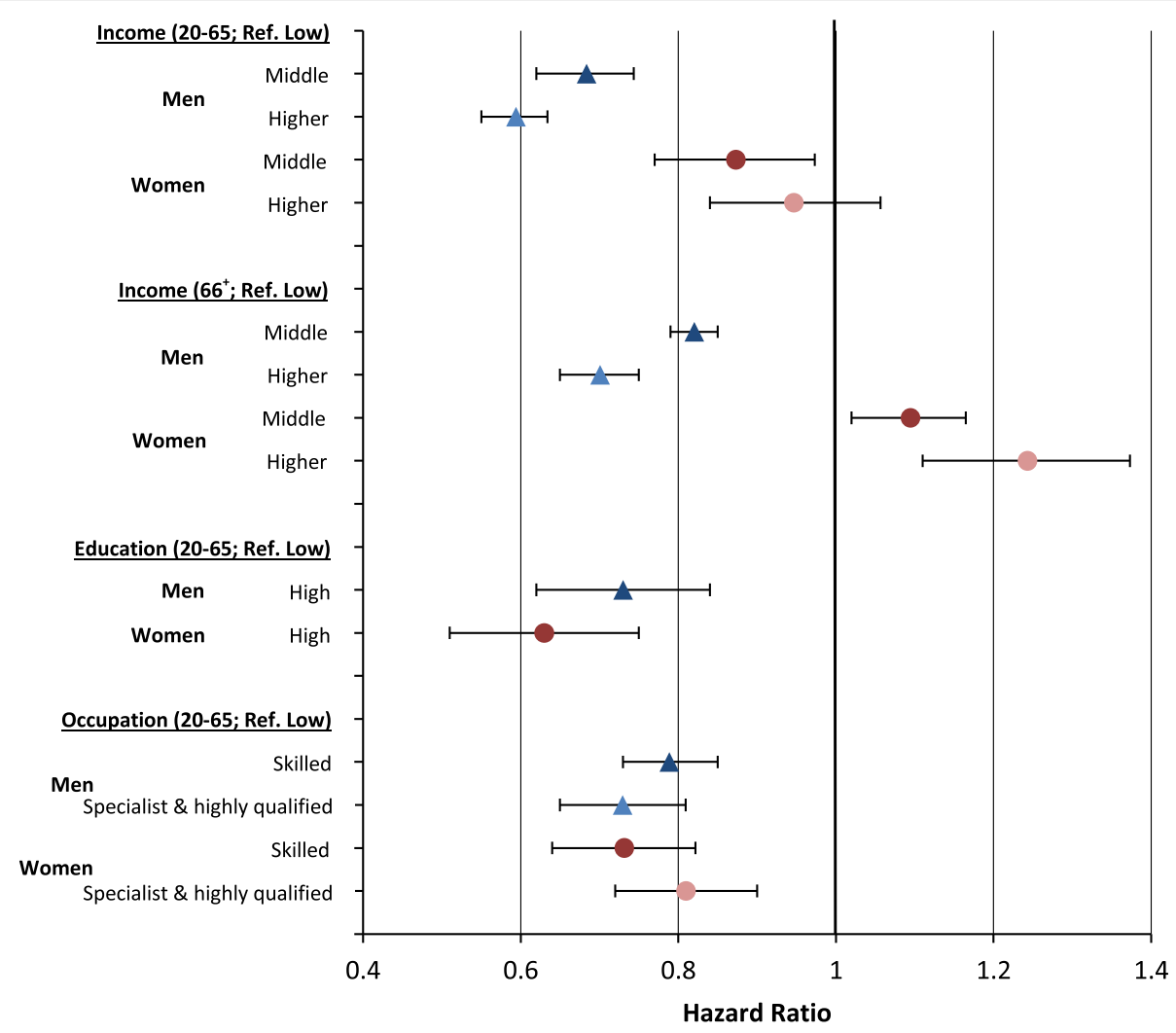

Fig. 1 Risks of lung cancer incidence by socioeconomic group, stratified by sex and age. Note: all analyses are controlled for age (in single-year age-groups as second-degree polynomial) and for period.

decreasing (age 20-65) or stable (age 66+) rates in the higher-income group (Fig. 6).

The educational inequalities in LC incidence among the working-age population narrowed over time. In particular, the tendency towards increasing rates among females and males with high educational level led to this converging trend between educational groups (Fig. 7).
With respect to occupational groups narrowing inequalities in LC incidence were observed over time. In men, the strong decrease in the rate of men without vocational training led to this development. In women, on the other hand, it is the rising incidence rate among skilled women with vocational training that led to this trend (Fig. 7).
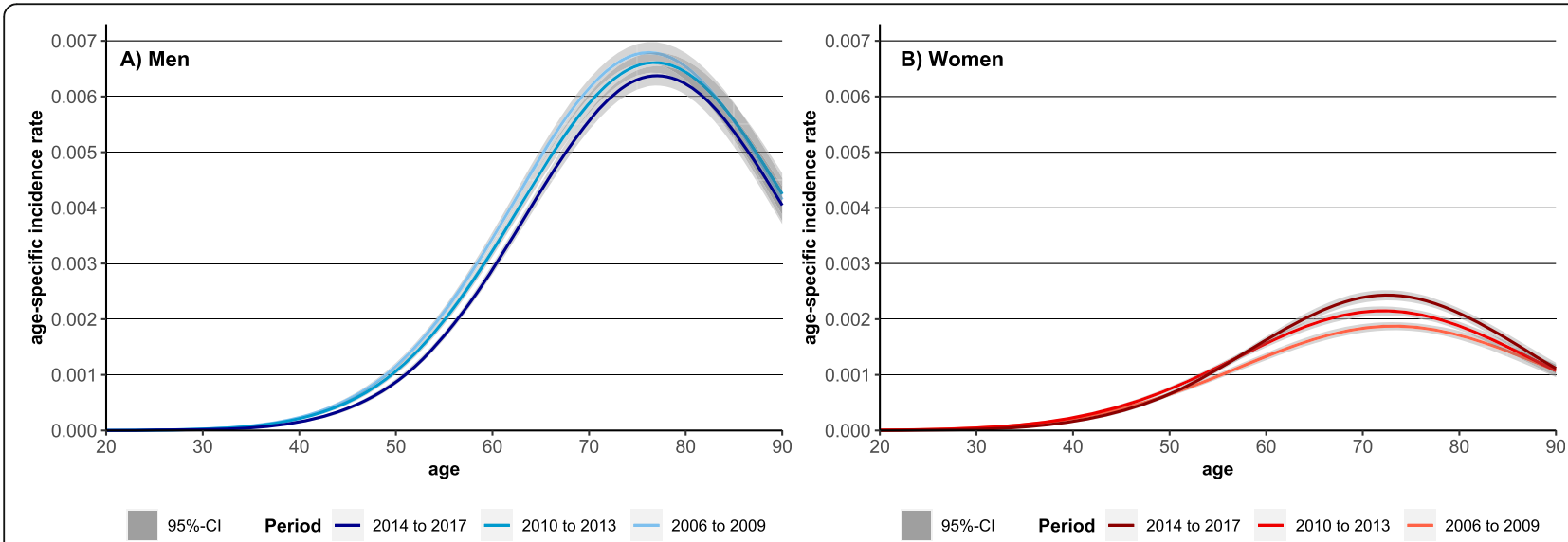

Fig. 2 Observed and predicted values for age-specific lung cancer incidence rates for the periods 2006-2009 and 2014-2017 by sex 

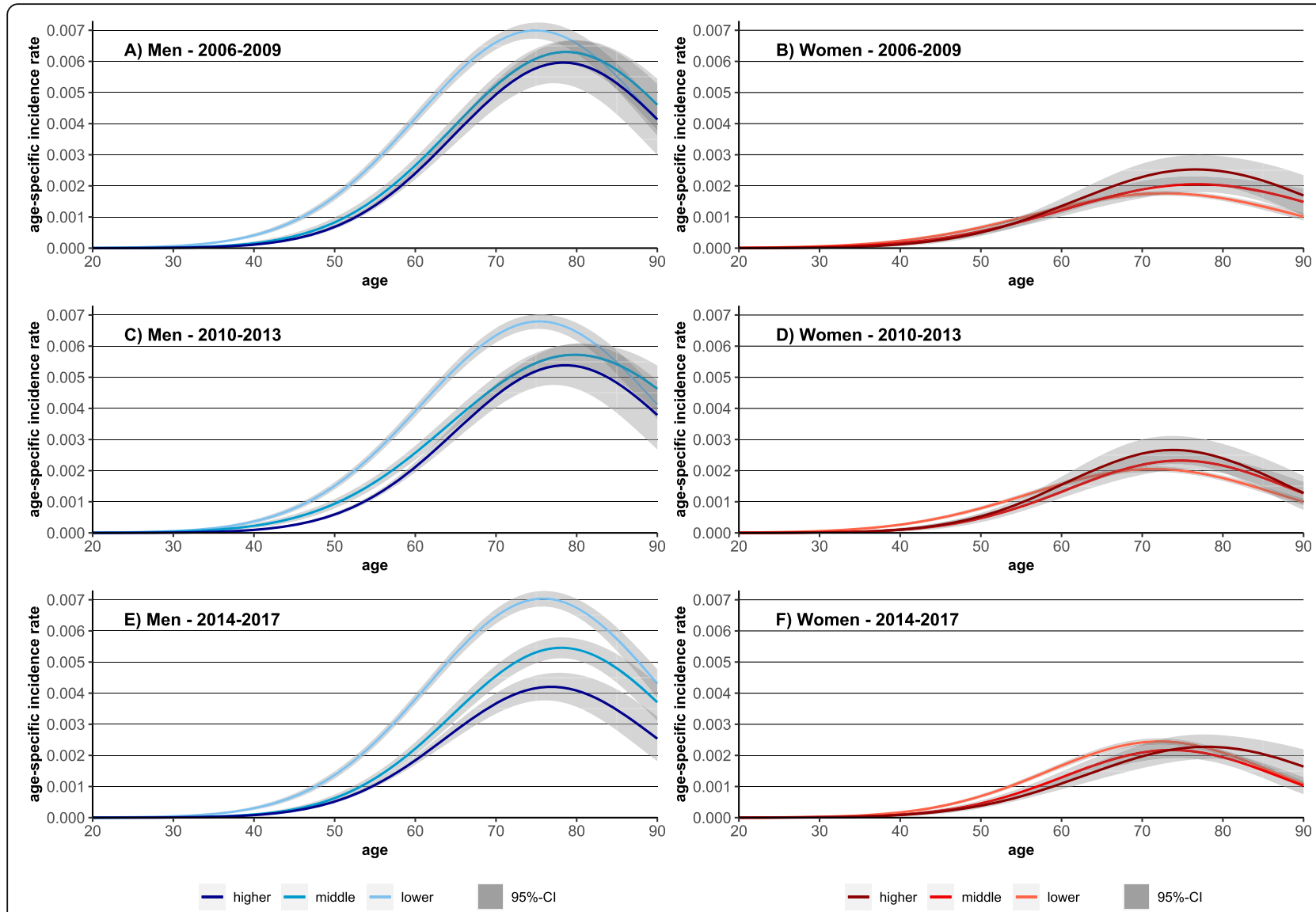

Fig. 3 Observed and predicted values for lung cancer incidence rates for the periods 2006-2009 and 2014-2017 by sex and income groups
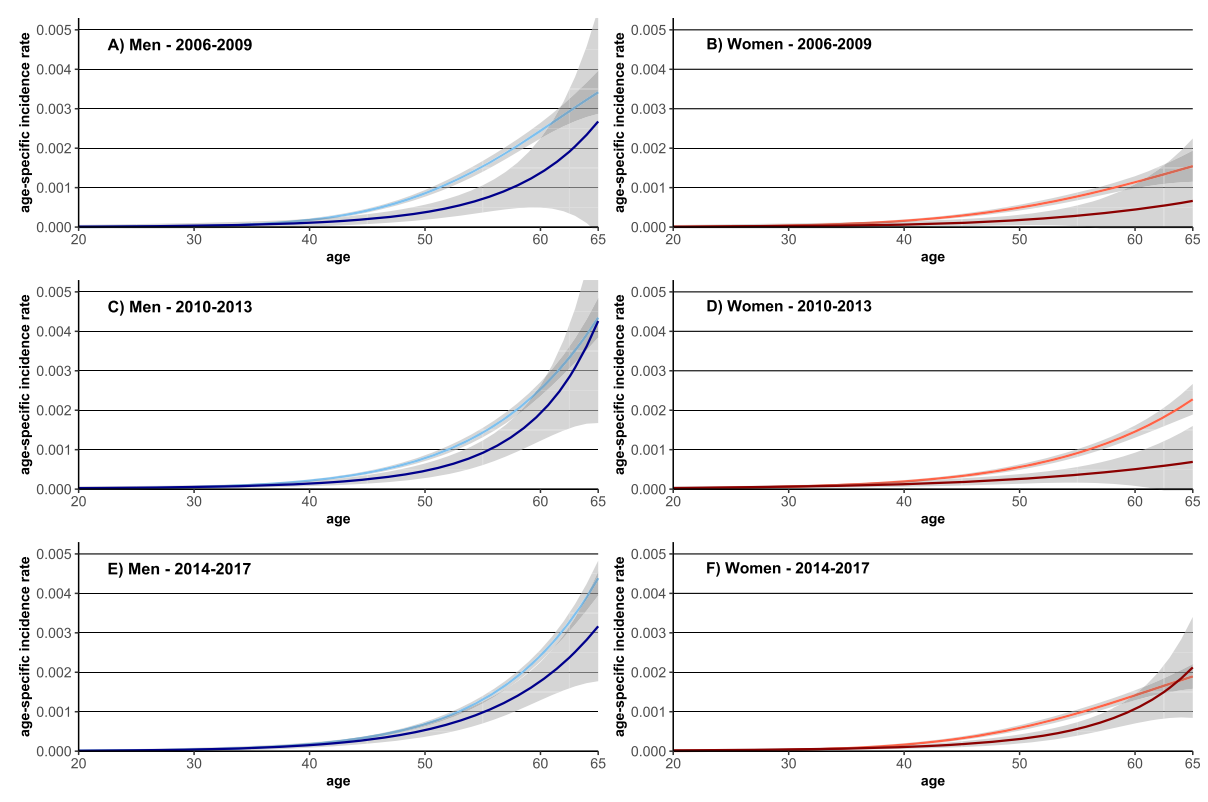

a5\%-Cl -12 and 13 years $-<12$ years

- $95 \%$-Cl -12 and 13 years $-<12$ years

Fig. 4 Observed and predicted values for age-specific lung cancer incidence rates for the periods 2006-2009 and 2014-2017 by sex and educational level 

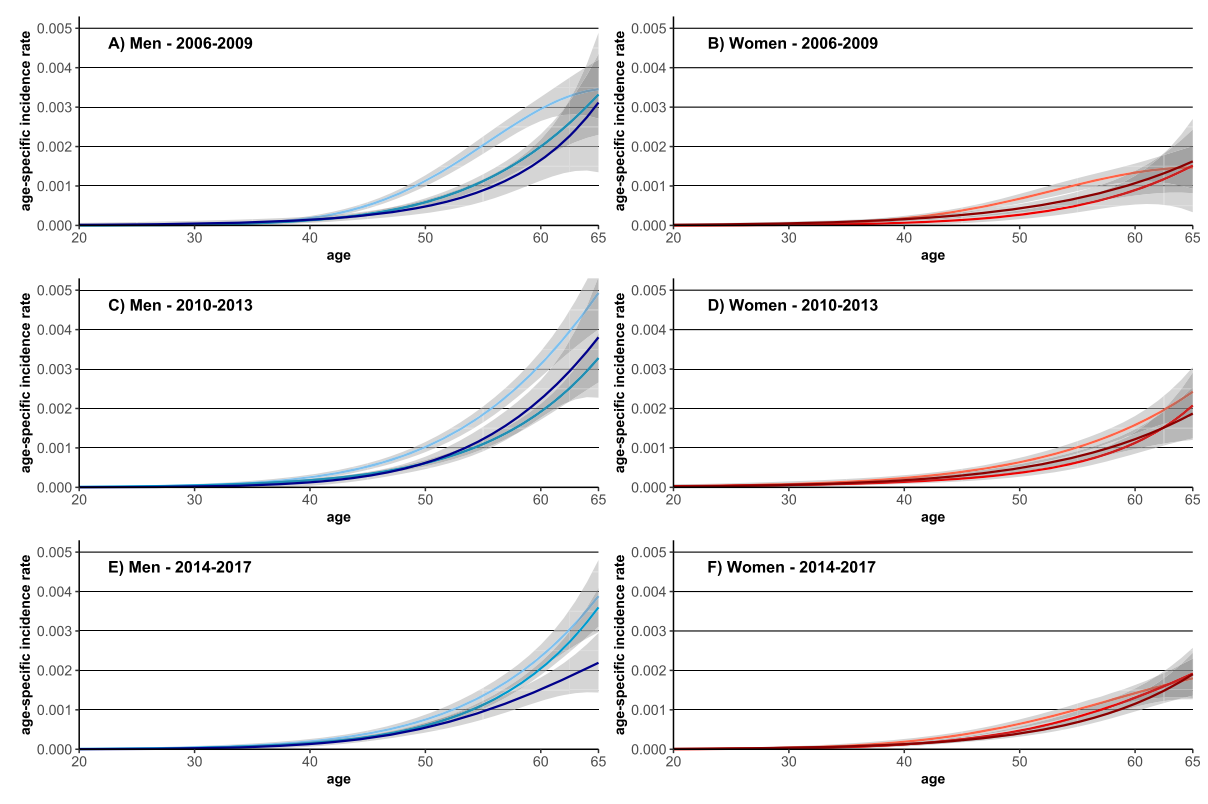

95\%-Cl - specialist \& highly qualified - skilled - unskilled

95\%-Cl - specialist \& highly qualified - skilled - unskilled

Fig. 5 Observed and predicted values for age-specific lung cancer incidence rates for the periods 2006-2009 and 2014-2017 by sex and occupational position
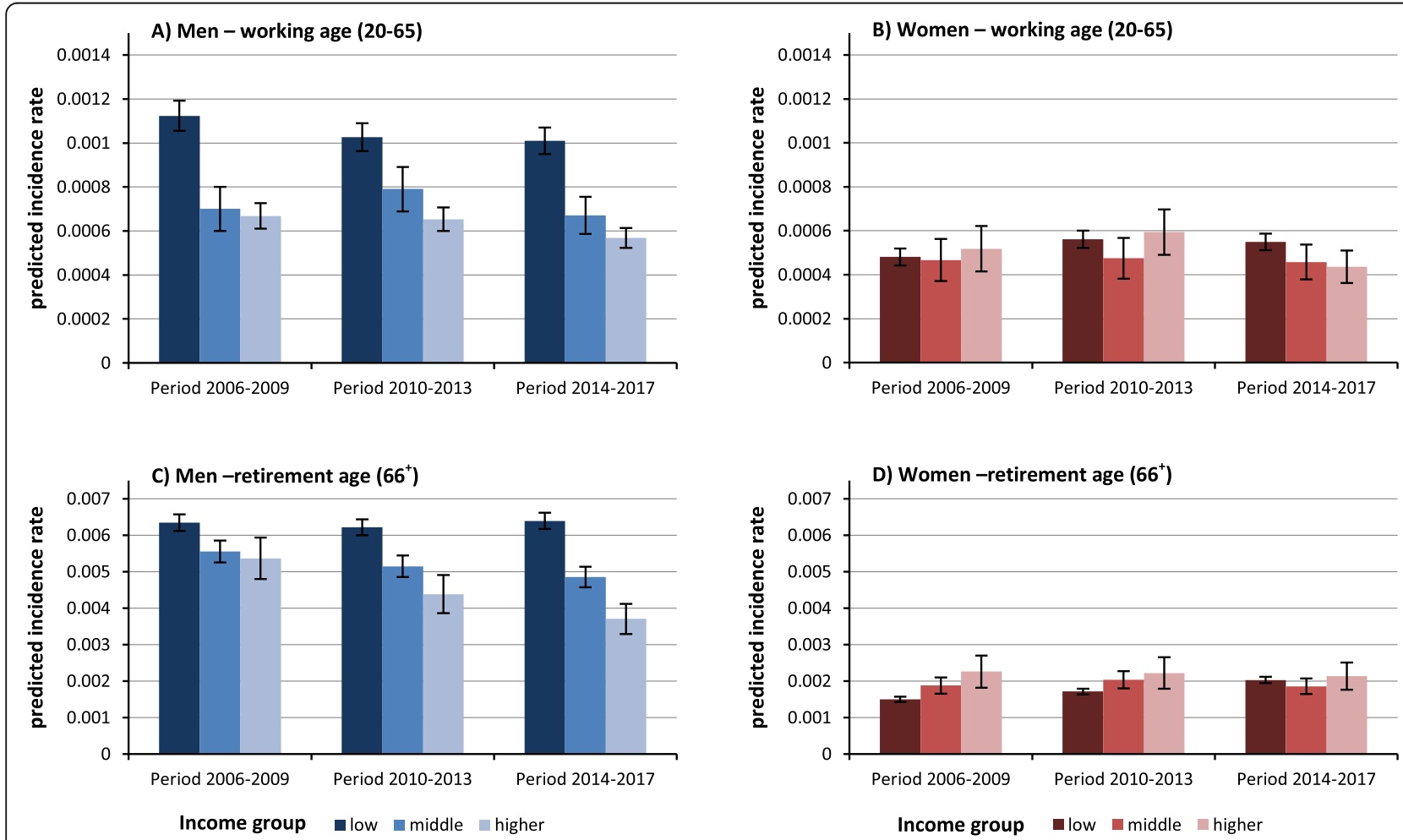

Fig. 6 Predicted lung cancer incidence rate by income group, stratified for age and sex. Note: all analyses are controlled for mean age in period (as second-degree polynomial), for period; the models for the working-age population include all three socioeconomic indicators (income, occupational position, educational level) the models for the retirement-age population include income. 


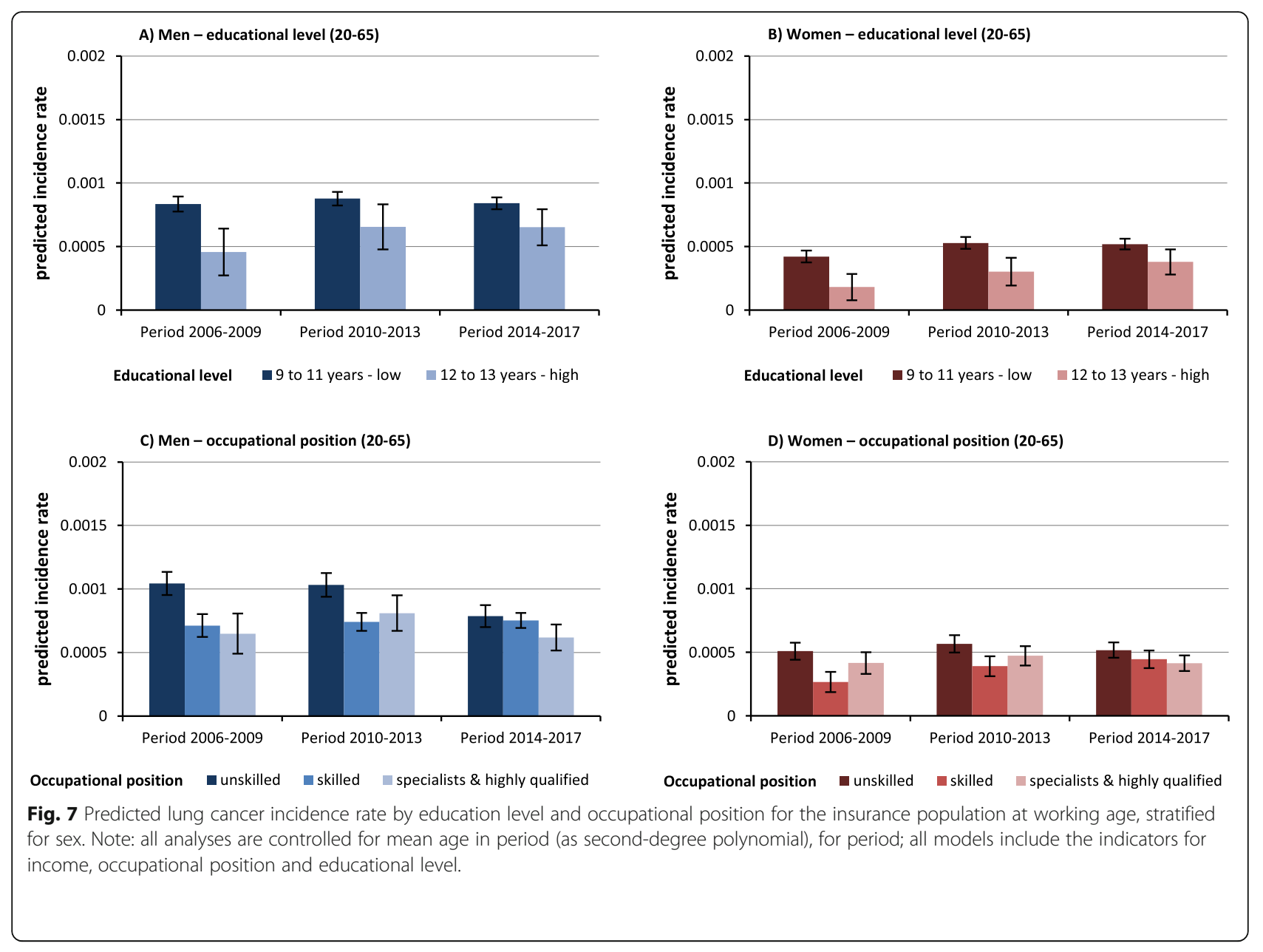

\section{Discussion}

The aim of the study was to investigate time trends in socioeconomic inequalities in LC incidence in Germany. Our results concerning time trends in sex-specific incidence of LC are in line with the official statistics for Germany [2]. We found decreasing incidence rates in LC for men and increasing rates for women. This development had an impact on the gap between the sexes as the differences were reduced over time. In accordance with previous research [7-16], our findings reveal higher social disparities in LC for men than for women. These disparities were most pronounced in terms of income inequalities in LC incidence in men. Driven by the decline in LC incidence among the middle- and higher-income group, income inequalities widened in men. This increase in inequalities was strongest in men at retirement-age. In contrast, a reversed income gradient was found among women in the period 2006-2009. Due to rising $\mathrm{LC}$ incidence rates among women with low incomes and the decline in rates among women at working age with higher incomes, this gradient disappeared over time. Among men at working-age, the strongest inequalities in LC incidence were found in terms of income, the weakest in terms of occupational group, while among women, educational inequalities were strongest. Overall, occupational and educational inequalities tend to narrow over time.

Our study is one of the few that examines time trends in socioeconomic inequalities in LC incidence [11, 12]. International studies reported increasing inequalities in terms of social deprivation levels in LC morbidity for men and women for Great Britain [12, 16] and New Zealand [11]. Our findings are in line with current findings on LC incidence by regional deprivation level in Germany based on cross-sectional data, which reported substantial inequalities in men but not in women without considering differences in the working-age and retirement-age population [9]. In our analyses we may have indirectly depicted the results of changing regimes in harmful smoking behaviour in the 1960s and 1970s $[18,21,25,33]$, especially in women with higher SES, which is in accordance with a recently published study [39]. This underlines the importance of analysing time trends in SES inequalities in LC since cross-sectional 
approaches do not allow to depict the dynamics in cancer incidence within the different SES groups over time. This holds especially true for women. Thus, our findings may depict the effect of increased efforts in smoking prevention of the last decades [22, 24]. It should be noted that established tobacco prevention measures in Germany are weaker than in other European countries. Although progress has been made (e.g. smoking ban in public places), stricter anti-smoking measures are often called for but have not yet been implemented [4, 44]. However, our findings of the present and a recent study [39] indicate that 20 to 30 years later previous efforts in smoking prevention seem to have an impact on LC rates in women and men. Nevertheless, smoking-related diseases are still among the main driving forces of sex differences in mortality in Germany [32]. In contrast to the development at retirement age, inequalities among the working-age population are persisting or tend to narrow over time. This holds for educational as well as for occupational inequalities. With respect to occupational inequalities, this can most probably be explained by increasing standards of occupational safety, which among other things, resulted in lower exposure of carcinogens in the working environment over time. Among women at working-age, inequalities were strongest in terms of education while income inequalities in LC were much weaker than in men. This may be explained by the overall lower income level among women, which persists even when men and women with the same level of education are compared [45].

The findings indicate that trends in social inequalities in LC incidence may vary between age groups or birth cohorts. This holds especially true for women. However, as the majority of incident cases lies above the age of 70 , the analyses concerning educational level and occupational positions are based on low numbers of incident cases. Therefore, it is important to continue to monitor developments to see whether trends in educational and occupational inequalities continue into old ages.

\section{Strengths and limitations}

Our study is based on health insurance data spanning the time period from 2005 to 2017 that provide high case numbers and includes information on individual diagnoses as well as on socioeconomic characteristics. This permitted to analyse time trends in social inequalities in LC based on three SES indicators and among different age groups.

A major strength of our data is that all information is available at individual level, which prevents economic fallacies in the interpretation of the results [39]. Furthermore, the data contain the complete insurance population and are therefore not subject to selection bias with regard to health status $[37-40,46]$. More detailed information on general strengths can be found in previous studies (e.g. [37-40]).

The precise information on individual income and high case numbers allow to obtain a detailed picture of the development in LC incidence in different income groups from age 20 to the oldest old as well as in the population subgroups at working and at retirement age. As for other studies based on health insurance data the results concerning income inequalities should be interpreted carefully since the data do not include information on household income (e.g. [37-40]). However, previous analyses have shown that social gradients in health obtained from estimates based on household income can largely be replicated using individual income, which suggests individual income to be an adequate measure to study social inequalities in health [47].

The data on educational graduation and occupational position are restricted to the population at working age. Due to this limitation, the analyses of trends in educational and occupational inequalities could not be conducted for individuals above age 65. It can be assumed that inequalities in LC caused by the former occupational position or the educational level persist into old age. Additional information on educational level and former occupation would have allowed a deeper insight into the developments of LC inequalities, especially among women, but cannot be analysed on the basis of our data.

As described in previous studies based on this data (e.g. [37-40], the data are representative for the total population of Germany in terms of sex and age structure but differ in terms of social distribution [36]. We addressed this limitation by stratifying or controlling all analyses for socioeconomic indicators. Therefore, the reported results should be unaffected.

\section{Conclusion}

Our study reveals that social inequalities in LC are considerable and that trends vary with respect to SES group. The findings indicate that income inequalities widened among the elderly, but occupational and educational differences remained fairly stable or even narrowed among the working-age population. Most disadvantaged are men at retirement age with low income, for whom the increase in inequalities was most pronounced. More research is needed to uncover the underlying mechanisms that explain the widening inequalities in men and the observed trends in women. Our findings indicate that time trends in LC differ not only with respect to SES but also according to age range or birth cohort. The findings also suggest that focussing on social inequalities without considering differences between age-groups and time trends in health inequalities could lead to existing inequalities remaining undetected. In LC, this holds 
especially for the trajectories in inequalities among women over time.

It is important to foster public health interventions (e.g. complete ban of tobacco advertising and smoking in public places) to reduce LC incidence in the German population. Against the backdrop of existing inequalities, interventions should mainly focus on deprived social groups.

\section{Abbreviations}

LC: lung cancer; SES: Socioeconomic status; AOKN: Allgemeine ortskrankenkasse niedersachsen; ICD-10: International classification of diseases 10th revision; HR: Hazard ratio

\section{Acknowledgements}

We thank the AOK Niedersachsen (Statutory Local Health Insurance of Lower Saxony) for providing the data. In particular, the support of Dr. Jürgen Peter, Dr. Jona Stahmeyer, and Dr. Sveja Eberhard made it possible to carry out this study.

\section{Authors' contributions}

FT and SG developed the idea and research questions of the study. FT analysed the data and wrote the first draft of the manuscript. JE and JT were major contributors to the final manuscript. JE, JT, HG, and SG contributed to the conception and discussion of the study and reviewed the work critically. All authors read and approved the final version of the manuscript.

\section{Funding}

JT's work is supported by the AOK Niedersachsen (Statutory Local Health Insurance of Lower Saxony) [grant number: not applicable] as part of an ongoing project on morbidity compression. JE's work is supported by the German Research Foundation (DFG) [grant number: GE 1167/15-1]. The funders had no role in study design, data collection and analysis, decision to publish, or preparation of the manuscript. Open Access funding enabled and organized by Projekt DEAL.

\section{Availability of data and materials}

The data analysed in this study are not publicly available due to protection of data privacy of the insured individuals by the AOK Niedersachsen (AOKNStatutory Local Health Insurance of Lower Saxony). The data underlying this study belong to the AOKN. Interested researchers can send data access requests to Jona Stahmeyer at the AOKN using the following e-mail address: Jona.Stahmeyer@aok.nds.de. The authors did not have any special access privileges.

\section{Declarations}

\section{Ethics approval and consent to participate}

Our study is based on claims data, i.e., on routinely collected data of a statutory health insurance provider. We confirm that all data are fully anonymised before we accessed them. The use of this sort of data for scientific purposes is regulated by federal law. The data protection officer of the Statutory Local Health Insurance of Lower Saxony (AOK Niedersachsen) has approved its use.

\section{Consent for publication}

Not applicable.

\section{Competing interests}

\section{None declared.}

\section{Author details}

${ }^{1}$ Institute for General Practice, Hannover Medical School, Hanover, Germany. ${ }^{2}$ Medical Sociology Unit, Hannover Medical School, Hanover, Germany. ${ }^{3}$ Comprehensive Cancer Center Hannover, Hannover Medical School, Hanover, Germany. ${ }^{4}$ Department of Pneumology, Hannover Medical School, Hanover, Germany.
Received: 13 November 2020 Accepted: 7 March 2021

Published online: 19 March 2021

\section{References}

1. Statstistisches Bundesamt. Causes of death in Germany. 12(4). Statistisches Bundesamt, editor. Wiesbaden; 2015.

2. Robert Koch-Institut. Krebs in Deutschland für 2015/2016. vol. 12. Robert Koch-Institut und die Gesellschaft der epidemiologischen Krebsregister in Deutschland e.V., editor. Berlin; 2019.

3. Quante AS, Ming C, Rottmann M, Engel J, Boeck S, Heinemann V, Westphalen CB, Strauch K. Projections of cancer incidence and cancerrelated deaths in Germany by 2020 and 2030. Cancer Med. 2016;5(9):264956. https://doi.org/10.1002/cam4.767.

4. John U, Hanke M. Age- and sex-specific trends in lung Cancer mortality over 62 years in a nation with a low effort in Cancer prevention. Int J Environ Res Public Health. 2016;13(4):362. https://doi.org/10.3390/ijerph13040362.

5. Lampert T, Hoebel J. Socioeconomic inequalities in health in later life. Z Gerontol Geriatr. 2019;52(1):91-9. https://doi.org/10.1007/s00391-018-01487-y.

6. Lampert T, Kroll LE, Kuntz B, Hoebel J. Health inequalities in Germany and in international comparison: trends and developments over time. J Health Monit. 2018;3(S1):1-24

7. Bryere J, Dejardin O, Bouvier V, Colonna M, Guizard AV, Troussard X, Pornet C, Galateau-Salle F, Bara S, Launay L, Guittet L, Launoy G. Socioeconomic environment and cancer incidence: a French population-based study in Normandy. BMC Cancer. 2014;14(1):87. https://doi.org/10.1186/1471-24 07-14-87.

8. Garcia-Gil M, Elorza JM, Banque M, Comas-Cufí M, Blanch J, Ramos R, Méndez-Boo L, Hermosilla E, Bolibar B, Prieto-Alhambra D. Linking of primary care records to census data to study the association between socioeconomic status and cancer incidence in southern Europe: a nationwide ecological study. PLoS One. 2014;9(10):e109706. https://doi.org/10.13 71/journal.pone.0109706.

9. Hoebel J, Kroll LE, Fiebig J, Lampert T, Katalinic A, Barnes B, Kraywinkel K. Socioeconomic inequalities in Total and site-specific Cancer incidence in Germany: a population-based registry study. Front Oncol. 2018:8:402. https://doi.org/10.3389/fonc.2018.00402.

10. Li X, Sundquist J, Zoller B, Sundquist K. Neighborhood deprivation and lung cancer incidence and mortality: a multilevel analysis from Sweden. J Thorac Oncol. 2015;10(2):256-63. https://doi.org/10.1097/jto.0000000000000417.

11. Teng AM, Atkinson J, Disney G, Wilson N, Blakely T. Changing socioeconomic inequalities in cancer incidence and mortality: cohort study with 54 million person-years follow-up 1981-2011. Int J Cancer. 2017;140(6): 1306-16. https://doi.org/10.1002/ijc.30555

12. Tweed EJ, Allardice GM, McLoone P, Morrison DS. Socio-economic inequalities in the incidence of four common cancers: a population-based registry study. Public Health. 2018;154:1-10. https://doi.org/10.1016/j.puhe.2 017.10.005.

13. van Raalte A, Myrskylä M, Martikainen P. The role of smoking on mortality compression: an analysis of Finnish occupational social classes, 1971-2010. Demogr Res. 2015:32(20):589-620. https://doi.org/10.4054/DemRes.2015.32.20.

14. Mari-Dell'Olmo M, Gotsens M, Palencia $L$, et al. Socioeconomic inequalities in cause-specific mortality in 15 European cities. J Epidemiol Community Health. 2015;69(5):432-41. https://doi.org/10.1136/jech-2014-204312.

15. Koch MB, Diderichsen F, Gronbaek M, Juel K. What is the association of smoking and alcohol use with the increase in social inequality in mortality in Denmark? A nationwide register-based study. BMJ Open. 2015;5(5): e006588. https://doi.org/10.1136/bmjopen-2014-006588.

16. Rowan S. Trends in cancer incidence by deprivation, England and Wales, 1990-2002. Health Stat Q. 2007:36:24-35.

17. Pampel FC, Krueger PM, Denney JT. Socioeconomic disparities in health behaviors. Annu Rev Sociol. 2010;36(1):349-70. https://doi.org/10.1146/a nnurev.soc.012809.102529.

18. Pampel FC, Bricard D, Khlat M, Legleye S. Life course changes in smoking by gender and education: a cohort comparison across France and the United States. Popul Res Policy Rev. 2017;36(3):309-30. https://doi.org/10.1007/ s11113-016-9424-y.

19. Caleyachetty R, Tehranifar P, Genkinger JM, Echouffo-Tcheugui JB, Muennig P. Cumulative social risk exposure and risk of cancer mortality in adulthood. BMC Cancer. 2015;15(1):945. https://doi.org/10.1186/s12885-015-1997-z.

20. Kuntz B, Waldhauer J, Moor I, Rathmann K, Richter M, Orth B, Piontek D, Kraus L, Zeiher J, Lampert T. Trends in educational inequalities in smoking 
among adolescents in Germany : evidence from four population-based studies. Bundesgesundheitsblatt Gesundheitsforschung Gesundheitsschutz. 2018;61(1):7-19. https://doi.org/10.1007/s00103-017-2636-4.

21. Pampel F, Legleye S, Goffette C, Piontek D, Kraus L, Khlat M. Cohort changes in educational disparities in smoking: France, Germany and the United States. Soc Sci Med. 2015;127:41-50. https://doi.org/10.1016/.socscimed.2014.06.033.

22. Wilson LM, Avila Tang E, Chander G, Hutton HE, Odelola OA, Elf JL, Heckman-Stoddard BM, Bass EB, Little EA, Haberl EB, Apelberg BJ. Impact of tobacco control interventions on smoking initiation, cessation, and prevalence: a systematic review. J Environ Public Health. 2012;2012:96172436. https://doi.org/10.1155/2012/961724.

23. Schulze A, Mons U. The evolution of educational inequalities in smoking: a changing relationship and a cross-over effect among German birth cohorts of 1921-70. Addiction. 2006;101(7):1051-6. https://doi.org/10.1111/j.13600443.2006.01458.x.

24. Jha P, Peto R. Global effects of smoking, of quitting, and of taxing tobacco. N Engl J Med. 2014:370(1):60-8. https://doi.org/10.1056/NEJMra1308383.

25. Zeiher J, Finger JD, Kuntz B, Hoebel J, Lampert T, Starker A. Trends in smoking among adults in Germany : evidence from seven population-based health surveys from 1991-2015. Bundesgesundheitsblatt Gesundheitsforschung Gesundheitsschutz. 2018:61(11):1365-76. https://doi. org/10.1007/s00103-018-2817-9

26. Schaap MM, Kunst AE, Leinsalu M, Regidor E, Ekholm O, Dzurova D, Helmert U, Klumbiene J, Santana P, Mackenbach JP. Effect of nationwide tobacco control policies on smoking cessation in high and low educated groups in 18 European countries. Tob Control. 2008;17(4):248-55. https://doi.org/1 0.1136/tc.2007.024265

27. van Meijgaard J, Fielding JE. Estimating benefits of past, current, and future reductions in smoking rates using a comprehensive model with competing causes of death. Prev Chronic Dis. 2012;9.

28. Thun M, Peto R, Boreham J, Lopez AD. Stages of the cigarette epidemic on entering its second century. Tob Control. 2012;21(2):96-101. https://doi. org/10.1136/tobaccocontrol-2011-050294.

29. Thun MJ, Carter BD, Feskanich D, Freedman ND, Prentice R, Lopez AD, Hartge P, Gapstur SM. 50-year trends in smoking-related mortality in the United States. N Engl J Med. 2013;368(4):351-64. https://doi.org/10.1056/ NEJMsa1211127.

30. Janssen F, van Poppel F. The adoption of smoking and its effect on the mortality gender gap in Netherlands: a historical perspective. Biomed Res Int. 2015;2015(12):370274. https://doi.org/10.1155/2015/370274.

31. Janssen F, Spriensma A. The contribution of smoking to regional mortality differences in the Netherlands. Demogr Res. 2012;27(9):233-60. https://doi. org/10.4054/DemRes.2012.27.9.

32. Luy M, Wegner-Siegmundt $\mathrm{C}$. The impact of smoking on gender differences in life expectancy: more heterogeneous than often stated. Eur J Pub Health. 2015;25(4):706-10. https://doi.org/10.1093/eurpub/cku211.

33. Piontek $\mathrm{D}$, Kraus $\mathrm{L}$, Müller $\mathrm{S}$, Pabst A. To what extent do age, period, and cohort patterns account for time trends and social inequalities in smoking? SUCHT. 2010:56(5):361-71. https://doi.org/10.1024/0939-5911/a000047.

34. Geyer $\mathrm{S}$, Hemstrom O, Peter R, Vagero D. Education, income, and occupational class cannot be used interchangeably in social epidemiology. Empirical evidence against a common practice. J Epidemiol Community Health. 2006;60(9):804-10. https://doi.org/10.1136/jech.2005.041319.

35. AOK Niedersachsen. Geschäftsbericht 2017. Remshalden-Grunbach: Wacker Offsetdruck GmbH; 2017.

36. Jaunzeme J, Eberhard S, Geyer S. How "representative" are SHI (statutory health insurance) data? Demographic and social differences and similarities between an SHI-insured population, the population of Lower Saxony, and that of the Federal Republic of Germany using the example of the AOK in Lower Saxony. Bundesgesundheitsblatt Gesundheitsforschung Gesundheitsschutz. 2013;56(3):447-54. https://doi.org/10.1007/s00103-012-1 626-9.

37. Tetzlaff J, Geyer S, Tetzlaff F, Epping J. Income inequalities in stroke incidence and mortality: trends in stroke-free and stroke-affected life years based on German health insurance data. PLoS One. 2020;15(1):e0227541. https://doi.org/10.1371/journal.pone.0227541.

38. Tetzlaff F, Epping J, Sperlich S, Tetzlaff J. Widening income inequalities in life expectancy? Analysing time trends based on German health insurance data. J Epidemiol Community Health. 2020;74(7):592-7. https://doi.org/10.1136/ jech-2019-212966
39. Tetzlaff F, Epping J, Golpon H, et al. Compression, expansion, or maybe both? Growing inequalities in lung cancer in Germany. PloS one. 2020;15: e0242433.

40. Tetzlaff J, Geyer S, Westhoff-Bleck M, Sperlich S, Epping J, Tetzlaff F. Social inequalities in mild and severe myocardial infarction: how large is the gap in health expectancies? BMC Public Health. 2021;21(1):259. https://doi.org/1 0.1186/s12889-021-10236-7.

41. Braveman PA, Cubbin C, Egerter S, Chideya S, Marchi KS, Metzler M, Posner S. Socioeconomic status in health research: one size does not fit all. Jama. 2005;294(22):2879-88. https://doi.org/10.1001/jama.294.22.2879.

42. Blossfeld H-P. Labor-market entry and the sexual segregation of careers in the Federal Republic of Germany. Am J Sociol. 1987;93(1):89-118. https:// doi.org/10.1086/228707.

43. Stata_Corp. Stata statistical software. release 14. College Station: Stata Corp; 2015

44. Joossens L, Feliu A, Fernandez E. The tobacco control scale 2019 in Europe. Brussels: Association of European Cancer Leagues, Catalan Institute of Oncology; 2020. Available from: http://www.tobaccocontrolscale.org/TCS201 9.pdf.

45. Federal Ministry for Family Affairs, Senior Citizens, Women and Youth. Pay inequality between men and women in Germany. Federal Ministry for Family Affairs, Senior Citizens, Women and Youth - BMFSFJ, editor. Berlin; 2009

46. Geyer S, Jaunzeme J. Möglichkeiten und Grenzen von Befragungsdaten und Daten gesetzlicher Krankenversicherungen. In: Swart E, Ihle P, Gothe H, Matusiewicz D, editors. Routinedaten im Gesundheitswesen: Handbuch Sekundärdatenanalyse: Grundlagen, Methoden und Perspektiven. 2nd ed. Bern: Verlag Hans Huber; 2014. p. 223-33.

47. Geyer S. Income, income, or income? The effects of different income measures on health in a national survey. J Epidemiol Community Health. 2011;65(6):491-6. https://doi.org/10.1136/jech.2009.103390.

\section{Publisher's Note}

Springer Nature remains neutral with regard to jurisdictional claims in published maps and institutional affiliations.

Ready to submit your research? Choose BMC and benefit from:

- fast, convenient online submission

- thorough peer review by experienced researchers in your field

- rapid publication on acceptance

- support for research data, including large and complex data types

- gold Open Access which fosters wider collaboration and increased citations

- maximum visibility for your research: over $100 \mathrm{M}$ website views per year

At $\mathrm{BMC}$, research is always in progress.

Learn more biomedcentral.com/submissions 